\title{
Estimating a Taylor Rule with Markov Switching Regimes for Switzerland
}

\author{
Alexander Perruchoud*
}

JEL-Classification: C11, C15, E52, E58.

Keywords: Taylor rule, Markov switching, Bayesian inference, Gibbs sampling.

\section{Introduction}

In his pioneering article TAYLOR (1993) described the Fed's setting of monetary policy as reacting to the output and inflation gap. The use of Taylor rules or more generally of monetary policy rules as an instrument to summarize a central bank's policy decisions is nowadays widespread. 'The term "rule", however, does not mean that the central bank conducts monetary policy mechanically. A monetary policy rule just describes a country's monetary policy with help of its main policy indicators.

As suggested by the Lucas (1976) critique, a problem with Taylor rules is that they seem to be too rigid with respect to their parameters. Several authors point to policy changes through time or depending on the state of the economy. For instance McNeEs (1986) claims,

A policy reaction function is likely to be a fragile creature. Over time [...] the importance attached to conflicting objectives may change, views on the structure of the economy may change.

A theoretical model with asymmetric, state-dependent monetary policy is given by Cukierman (1999), where the central bank is less willing to counteract inflation during a recession than during a boom. See also Ruge-Murcia (2001), who

* Department of Economics, University of California, San Diego, aperruchoud@ucsd.edu. I am grateful for helpful comments provided by Peter Kugler, Stefan Gerlach, two anonymous referees, and seminar participants at the University of Bern. Of course, all remaining errors are mine.

1 The literature sometimes defines a Taylor rule to be a specific type of monetary policy rule, i.e. the interest rate is determined by a constant, the output and inflation gap. In the following, the terms "Taylor rule" and "monetary policy rule" are used interchangeably. 
constructs a model based on asymmetric preferences of the central bank regarding unemployment. Persson and Tabellini (1999) argues that political pressure may be a cause for an asymmetric objective function of the central bank. This line of argument may be especially true for the period when the independence of many central banks was not yet institutionalized. GerLaCH (2003) analyzes the effects of a central bank with a non-constant output target. Specifically, the output target depends on the size of the supply shock, which may result in asymmetric monetary policies, e.g. recession aversion. A different reasoning for time-varying parameters is put forward by Smets (1998) and Rudebusch (2001). They show that data uncertainty, particularly regarding the output gap, can lead to non-constant parameters in the optimal policy rule. Another rationale for changing parameters in inflation-forecast based rules is given in Amano, Coletti, and Macklem (1999). They show that in order for the central bank to benefit from increased credibility in the form of lower inflation and output volatility, it has to adjust its policy rule else the variability of inflation and output may even increase.

This literature and the current popularity of econometric models with timevarying parameters has spurred a renewed interest in this area of research. Hamilton (1989) shows how to estimate an autoregression with parameters varying subject to a discrete state Markov process. In his article, he proposes a nonlinear filter which uses the observed data to conduct inference concerning the unobserved states. An application of this methodology to monetary policy rules is conducted by Wesche (2003). ${ }^{2}$ She estimates state-dependent Taylor rules for France, Germany, Italy, the United Kingdom, and the United States. The parameters entering the rule are assumed to change according to a two state Markov process. She finds evidence of asymmetric monetary policy. One regime is associated with a high weight on inflation and the other regime reacts strongly to output deviations from target. Rabanal (2004) and Owyang and RameY (2004) reach similar conclusions for the United States. According to Rabanal (2004), the Federal Reserve targets inflation during expansions, while during recessions it focuses on output growth. OWYANG and RAMEY (2004) use Markov switching methods to measure U.S. monetary policy in a simple model. Their results suggest the presence of a "dove regime", which accommodates increases in the natural rate of unemployment, and a "hawk regime", in which this is not the case. State-dependent Taylor rules for the Euro Area and the United Kingdom are estimated in Altavilla and Landolfo (2005). Their Markov switching

2 See Assenmacher-Wesche (2006) for a revised version of her paper. 
VAR model finds an aggressive and a less aggressive regime. The former is characterized by an aggressive reaction to the state of the economy and is related to periods of low output growth. KuzIN (2006) applies a backward-looking Taylor rule with a Markov switching parameter on inflation to German data. He finds periods of high and low inflation aversion in the Bundesbank's monetary policy. An interesting approach is put forward by SIMS and ZHA (2006) who check for regime switches in U.S. monetary policy with help of a multivariate model that allows for Markov switching in coefficients and variances. However, they conclude that the model with state-dependent variances and constant coefficients performs best in terms of model fit.

Being a small open economy, the exchange rate plays an important role in Switzerland's monetary policy, e.g. a profound appreciation of the Swiss franc increases the pressure on the Swiss National Bank to lower interest rates. Article 99 of the Swiss federal constitution commits the SNB to follow a monetary policy in the interests of the country as a whole. The importance of the external sector to the Swiss economy, therefore, requires watching the exchange rate path closely. Although inflation and the output gap are its primary targets, it also has to take the exchange rate into account when deciding on its policy. RicH (1997) provides supporting evidence. He concludes that the main adjustments of the SNB's policy were due to shifts in demand for money and to exchange rate movements.

In this paper a Taylor rule, which includes the exchange rate gap, is estimated for Switzerland. In order to account for the state-contingent nature of the SNB's monetary policy, the Taylor rule is enhanced with parameters depending on two states governed by a Markov switching process. An attractive feature of Markov switching models is that no restrictions regarding the size, sign, or the state at a particular point in time have to be imposed on the parameters in estimation, but are all determined by the data.

The rest of the paper is structured as follows. Section 2 formulates the model to be estimated. The Taylor rule includes the output gap, inflation, and the exchange rate gap, and allows for interest rate smoothing. The coefficients and the variance are state-dependent. The two states follow a Markov process with constant transition probabilities. In Section 3 the estimation methodology is illustrated. A Gibbs sampler is used to estimate the model. The data and the results are presented in Sections 4 and 5, respectively. Finally, Section 6 concludes. 


\section{Model}

This section shows the structure of the most general Taylor rule I specify in this paper. In the next section and the Appendix the estimation methodology for this general model structure is presented. Section 5, then, presents estimation results for different model specifications, e.g. not all parameters are state-dependent or only the variance of the error term is state-dependent and so on. Before going into the details of the model, let me mention the following caveat. ${ }^{3}$ The coefficients in the Taylor rule cannot be interpreted directly as preference parameters of a central bank. Using a simple model composed of a loss function for the monetary authority, a Phillips and an IS curve, Svensson (1999) concludes that the resulting Taylor-type equation is a reduced form where the coefficients depend not only on the central bank's weights it puts on its targets but also on parameters that describe the structure of the economy. In this paper, I assume that the IS and Phillips curve have parameters that are constant across regimes. With this qualification it is valid to make relative statements about the central bank's preferences. E.g. if the coefficient on inflation is bigger in state 1 than in state 0 , we can say that the monetary authority puts more weight on inflation in state 1 than in state 0 .

The central bank's desired target nominal interest rate, $i_{t}^{*}$, is given by

$$
\begin{aligned}
i_{t}^{*} & =\beta_{0 S_{t}}+\beta_{1 S_{t}}[\underbrace{E\left(y_{t+k}\right)-y_{t+k}^{*}}_{\tilde{y}_{t+k}}] \\
& +\beta_{2 S_{t}}\left[E\left(\pi_{t+q}\right)-\pi_{S_{t}^{*}}^{*}\right]+\beta_{3 S_{t}}[\underbrace{E\left(e_{t+w}\right)-e_{t+w}^{*}}_{\tilde{e}_{t+w}}],
\end{aligned}
$$

where $y_{t}$ is actual output, $y_{t}^{*}$ is the target level of output, $\tilde{y}_{t}$ is the expected output gap, $\pi_{t}$ is inflation, $\pi_{S_{t}}^{*}$ is the state-dependent target level of inflation, ${ }^{4} e_{t}$ is the real exchange rate, $e_{t}^{*}$ is the trend level of the real exchange rate, $\tilde{e}_{t}$ is the expected real exchange rate gap, and $E$ is the expectation operator. ${ }^{5}$ Thus, the monetary authority is assumed to react directly to the expected output gap in $t+k$, the

3 I thank the referees for pointing this out.

4 Note that for simplicity the target level of inflation depends on the central bank's current $\left(\pi_{S_{t}}^{*}\right)$ and not future $\left(\pi_{S_{t+q}}^{*}\right)$ preferences.

5 See GerLach-Kristen (2003) for an interest rate reaction function including also a long-term interest rate in order to approximate for inflation expectations. 
expected inflation gap in $t+q$, and the expected exchange rate gap in $t+w$. The indexation of the parameters by $S_{t}$ is due to the adoption of a state-dependent Taylor rule. I account for interest rate smoothing by including the lagged dependent variable as explanatory variable resulting in the following equation for the observed nominal rate of interest, $i_{t}$,

$$
\begin{aligned}
& i_{t}=\left(1-\rho_{S_{t}^{\rho}}\right) i_{t}^{*}+\rho_{S_{t}^{\rho}} i_{t-1}+u_{t}, 0 \leq \rho_{S_{t}^{\rho}}<1, \\
& u_{t} \sim N\left(0, \sigma_{S_{t}^{\sigma}}^{2}\right),
\end{aligned}
$$

where $\rho_{S_{t}^{\rho}}$ is the smoothing parameter which depends on a different state $S_{t}^{\rho}$. Hence, the observed interest rate is a weighted average of the central bank's target interest rate and the observed interest rate from last period. The smaller $\rho$ the faster $i_{t}$ approaches its target value $i_{t}^{*}$. The error term $u_{t}$ summarizes the part of monetary policy left unexplained by the variables in the Taylor rule, i.e. monetary policy shocks. These shocks can be generated from external influences, mistakes, or by systematic and loose reactions of the central bank to variables not included in the monetary policy rule. $u_{t}$ is assumed to be normally distributed with zero mean and a state-dependent variance. The variance depends on a different state $\left(S_{t}^{\sigma}\right)$ than the smoothing parameter and the coefficients in the target interest rate. If it would depend on the same state, then the regimes would only capture periods of high and low interest rate volatility, which is not the objective of this analysis.

In the estimation process I do not give $\pi_{S_{t}}^{*}$ a specific value. Instead, I rewrite (1) as

$$
i_{t}^{*}=\delta_{S_{t}}+\beta_{1 S_{t}} \tilde{y}_{t+k}+\beta_{2 S_{t}} E\left(\pi_{t+q}\right)+\beta_{3 S_{t}} \tilde{e}_{t+w},
$$

where

$$
\delta_{S_{t}}=\beta_{0 S_{t}}-\beta_{2 S_{t}} \pi_{S_{t}}^{*}
$$

6 For a theoretical justification of interest rate smoothing by central banks see Woodford (1999). He argues that inflation and output react primarily to variations in longer-term interest rates as opposed to the federal funds rate. Longer-term interest rates in turn are determined by private sector's expectations of future short-term interest rates. Hence, if the Fed can credibly commit to change future short-term rates in the same direction, only small initial changes in the federal funds rate are necessary to achieve its goals. 
In equilibrium, output, inflation, and the exchange rate equal their targets. Assuming a state-independent real interest rate in equilibrium $r^{*}$, the statedependent target level of inflation can be computed

$$
\pi_{S_{t}}^{*}=\frac{r^{*}-\delta_{S_{t}}}{\beta_{2 S_{t}}-1}
$$

Given the large sample range, I approximate the equilibrium real interest rate by the sample average of $\left(i_{t}-\pi_{t}\right)$, i.e. $r^{*}=1.28$.

The interest rate rule has to satisfy $\beta_{1 S_{t}}>0, \beta_{2 S_{t}}>1$, and $\beta_{3 S_{t}}<0$ in order to be stabilizing. If these conditions are satisfied, deviations of output and inflation above target are counteracted by higher real interest rates and positive exchange rate gaps are reduced by lower real interest rates. The requirement $\beta_{2 S_{t}}>1$ is known as the Taylor principle.

Substituting for $i_{t}^{*}$ in equation (2) yields the Taylor rule to be estimated

$$
i_{t}=\left(1-\rho_{S_{t}^{\rho}}\right)\left[\delta_{S_{t}}+\beta_{1 S_{t}} \tilde{y}_{t+k}+\beta_{2 S_{t}} E\left(\pi_{t+q}\right)+\beta_{3 S_{t}} \tilde{e}_{t+w}\right]+\rho_{S_{t}^{\rho}} i_{t-1}+u_{t} .
$$

In the most general specification, the unknown parameters depend on three sets of states, $S, S^{\rho}, S^{\sigma}$, which each can take on two different values, i.e. 0 or 1 . The parameters in the target interest rate depend on $S_{t}$, the smoothing parameter depends on a different state $S_{t}^{\rho}$, and, finally, the variance depends on $S_{t}^{\sigma}$. Hence,

$$
\begin{aligned}
\rho_{S_{t}^{\rho}} & =\rho_{0}\left(1-S_{t}^{\rho}\right)+\rho_{1} S_{t}^{\rho}, \\
\delta_{S_{t}} & =\delta_{0}\left(1-S_{t}\right)+\delta_{1} S_{t}, \\
\beta_{1 S_{t}} & =\beta_{10}\left(1-S_{t}\right)+\beta_{11} S_{t}, \\
\beta_{2 S_{t}} & =\beta_{20}\left(1-S_{t}\right)+\beta_{21} S_{t}, \\
\beta_{3 S_{t}} & =\beta_{30}\left(1-S_{t}\right)+\beta_{31} S_{t}, \\
\sigma_{S_{t}^{\sigma}}^{2} & =\sigma_{0}^{2}\left(1+h S_{t}^{\sigma}\right), \\
S_{t}^{\rho}, S_{t}, S_{t}^{\sigma} & =0,1 .
\end{aligned}
$$

7 I implicitly equate the SNB's target level of output with potential output. Hence, I do not consider the problem of time inconsistency brought up by Kydland and Prescott (1977) and BARRO and GORDON (1983). 
In order to simplify future notation I rewrite (7) as

$$
i_{t}=\left(1-\rho_{S_{t}^{\rho}}\right) x_{t^{\prime}} \boldsymbol{\beta}+\rho_{S_{t}^{\rho}} i_{t-1}+u_{t}
$$

where

and

$$
\begin{aligned}
x_{t}= & {\left[1-S_{t}, S_{t},\left(1-S_{t}\right) \tilde{y}_{t+k}, S_{t} \tilde{y}_{t+k},\left(1-S_{t}\right) E\left(\pi_{t+q}\right),\right.} \\
& \left.S_{t} E\left(\pi_{t+q}\right),\left(1-S_{t}\right) \tilde{e}_{t+w}, S_{t} \tilde{e}_{t+w}\right]^{\prime}
\end{aligned}
$$

$$
\boldsymbol{\beta}=\left[\delta_{0}, \delta_{1}, \beta_{10}, \beta_{11}, \beta_{20}, \beta_{21}, \beta_{30}, \beta_{31}\right]^{\prime} .
$$

The two states of each latent variable follow a first order Markov process with the transition probabilities denoted by

$$
\begin{aligned}
& p^{i j}=P\left(S_{t}=j \mid S_{t-1}=i\right), \\
& q^{i j}=P\left(S_{t}^{\rho}=j \mid S_{t-1}^{\rho}=i\right), \\
& r^{i j}=P\left(S_{t}^{\sigma}=j \mid S_{t-1}^{\sigma}=i\right) .
\end{aligned}
$$

Defining a new state variable $\tilde{S}_{t}$ will be convenient for the Gibbs sampling algorithm later on.

$\begin{array}{lccc} & S_{t}: & S_{t}^{\rho}: & S_{t}^{\sigma}: \\ \tilde{S}_{t}=1: & 0 & 0 & 0 \\ \tilde{S}_{t}=2: & 1 & 0 & 0 \\ \tilde{S}_{t}=3: & 0 & 1 & 0 \\ \tilde{S}_{t}=4: & 1 & 1 & 0 \\ \tilde{S}_{t}=5: & 0 & 0 & 1 \\ \tilde{S}_{t}=6: & 1 & 0 & 1 \\ \tilde{S}_{t}=7: & 0 & 1 & 1 \\ \tilde{S}_{t}=8: & 1 & 1 & 1\end{array}$




\section{Methodology}

The methodology for estimating the Taylor rule in (15) is based on Albert and Chib (1993) as well as Kim and Nelson (1999). Let $Y_{t}$ and $\tilde{S}_{t}$ be a vector containing all observations through time $t$

$$
\begin{gathered}
Y_{t}=\left[i_{t}, z_{t}, z_{t-1}, \ldots\right]^{\prime}, \\
z_{t}=\left[\tilde{y}_{t+k}, E\left(\pi_{t+q}\right), \tilde{e}_{t+w}, i_{t-1}\right]^{\prime}
\end{gathered}
$$

and the state vector

$$
\tilde{S}_{T}=\left[\tilde{S}_{0}, \tilde{S}_{1}, \ldots, \tilde{S}_{T}\right]^{\prime},
$$

respectively. The vector of parameters is denoted by

$$
\boldsymbol{\theta}=\left[\boldsymbol{\rho}, \boldsymbol{\beta}, \sigma_{0}^{2}, \sigma_{1}^{2}, p^{00}, p^{11}, q^{00}, q^{11}, r^{00}, r^{11}\right]^{\prime},
$$

where

$$
\rho=\left[\rho_{0}, \rho_{1}\right]^{\prime} .
$$

Furthermore, the notation $\boldsymbol{\theta}_{-p^{00}}^{j}$ is used to denote all the elements in $\boldsymbol{\theta}$ except for $p^{00}$

$$
\boldsymbol{\theta}_{-p^{j 0}}^{j}=\left[\boldsymbol{\rho}^{j}, \boldsymbol{\beta}^{j},\left(\sigma_{0}^{2}\right)^{j},\left(\sigma_{1}^{2}\right)^{j},\left(p^{11}\right)^{j-1},\left(q^{00}\right)^{j-1},\left(q^{11}\right)^{j-1},\left(r^{00}\right)^{j-1},\left(r^{11}\right)^{j-1}\right]^{\prime},
$$

with all elements ordered before $p^{00}$ coming from iteration round $j$ of the Gibbs sampler and the rest from the previous iteration $j-1$. Here is a rough summary of the Gibbs sampling methodology followed.

1. Draw $\boldsymbol{\rho}^{j}$ from $\boldsymbol{\rho} \mid Y_{T}, \tilde{\boldsymbol{S}}_{T}^{j-1}, \boldsymbol{\theta}_{-\rho}^{j}$.

2. Draw $\boldsymbol{\beta}^{j}$ from $\boldsymbol{\beta} \mid Y_{T}, \tilde{\boldsymbol{S}}_{T}^{j-1}, \boldsymbol{\theta}_{-\beta}^{j}$.

3. Draw $\left(\sigma_{0}^{2}\right)^{j}$ and $\left(\sigma_{1}^{2}\right)^{j}$ from $\sigma_{0}^{2} \mid Y_{T}, \tilde{\boldsymbol{S}}_{T}^{j-1}, \theta_{-\sigma_{0}^{2}}^{j}$ and $\sigma_{1}^{2} \mid Y_{T}, \tilde{\boldsymbol{S}}_{T}^{j-1}, \boldsymbol{\theta}_{-\sigma_{1}^{2}}^{j}$, respectively.

4. Draw $\tilde{\boldsymbol{S}}_{T}^{j}$ from $\tilde{\boldsymbol{S}}_{T} \mid Y_{T}, \boldsymbol{\theta}^{j}$.

5. Draw $\left(p^{00}\right)^{j}$ and $\left(p^{11}\right)^{j}$ from $p^{00} \mid Y_{T}, \tilde{\boldsymbol{S}}_{T}^{j}, \boldsymbol{\theta}_{-p^{j 0}}^{j}$ and $p^{11} \mid Y_{T}, \tilde{\boldsymbol{S}}_{T}^{j}, \boldsymbol{\theta}_{-p^{j 1}}^{j}$, respectively. 
6. Draw $\left(q^{00}\right)^{j}$ and $\left(q^{11}\right)^{j}$ from $q^{00} \mid Y_{T}, \tilde{S}_{T}^{j}, \boldsymbol{\theta}_{-q^{j 0}}^{j}$ and $q^{11} \mid Y_{T}, \tilde{S}_{T}^{j}, \theta_{-q^{11}}^{j}$, respectively. 7. Draw $\left(r^{00}\right)^{j}$ and $\left(r^{11}\right)^{j}$ from $r^{00} \mid Y_{T}, \tilde{S}_{T}^{j}, \boldsymbol{\theta}_{-r^{00}}^{j}$ and $r^{11} \mid Y_{T}, \tilde{\boldsymbol{S}}_{T}^{j}, \boldsymbol{\theta}_{-r^{11}}^{j}$, respectively.

A detailed description of the individual Gibbs sampler steps is delivered in the Appendix.

Before calculating the conditional posterior distributions, the priors have to be chosen. For convenience, conjugate priors are specified. The state-dependent variance of the error terms $\sigma_{S_{t}^{\sigma}}^{2}$ has an inverted Gamma prior

$$
\begin{gathered}
\sigma_{0}^{2} \sim I G\left(b^{0} / 2, B^{0} / 2\right), \\
(1+h) \sim I G\left(b^{0} / 2, B^{0} / 2\right) \mathrm{I}(h>0),
\end{gathered}
$$

where $\mathrm{I}(h>0)$ is an indicator function which identifies state 1 as the high variance state. For $\boldsymbol{\rho}$ and $\boldsymbol{\beta}$ normal priors are assumed

$$
\begin{aligned}
& \boldsymbol{\rho} \sim N\left(\boldsymbol{u}^{0}, U^{0}\right) \mathrm{I}(\text { stat. }) \mathrm{I}\left(\rho_{0}>\rho_{1}\right), \\
& \boldsymbol{\beta} \sim N\left(\boldsymbol{m}^{0}, M^{0}\right) \mathrm{I}\left(\beta_{6}>\beta_{5}\right),
\end{aligned}
$$

where I(stat.) is an indicator function guaranteeing stationarity of the system, i.e. $\left|\rho_{i}\right|$ has to be smaller than one. $\mathrm{I}\left(\rho_{0}>\rho_{1}\right)$ and $\mathrm{I}\left(\beta_{6}>\beta_{5}\right)$ are also indicator functions equalling 1 if $\rho_{0}>\rho_{1}$ and $\beta_{6}>\beta_{5}$ are true, respectively. These constraints are needed for identification purposes and can be accomplished by rejection sampling. Finally, for the transition probabilities I specify beta priors

$$
\begin{aligned}
& p^{i i} \sim \operatorname{beta}\left(w^{i i}, w^{i j}\right), \text { for } i, j=0,1, i \neq j, \\
& q^{i i} \sim \operatorname{beta}\left(w^{i i}, w^{i j}\right), \text { for } i, j=0,1, i \neq j, \\
& r^{i i} \sim \operatorname{beta}\left(w^{i i}, w^{i j}\right), \text { for } i, j=0,1, i \neq j .
\end{aligned}
$$

The hyperparameters are reproduced in Table 1. I choose them such that the priors are pretty non-informative.

The results reported below are based on 50,000 iterations of the Gibbs sampler. In order to ensure that the effect of the intial values has worn off, the first 5,000 draws are discarded. ${ }^{8}$

8 Using different starting values had no effect on the results. 
Table 1: Hyperparameters

\begin{tabular}{ll|ll}
\hline$\sigma^{2}:$ & $b^{0}=0.01, B^{0}=0.01$ & $\rho:$ & $u^{0}=0, U^{0}=I_{2}$ \\
$\boldsymbol{\beta}:$ & $m^{0}=0, M^{0}=10 I_{8}$ & $p^{00}, q^{00}, r^{00}:$ & $w^{00}=0, w^{01}=0$ \\
$p^{1}, q^{11}, r^{11}:$ & $w^{11}=0, w^{10}=0$ & & \\
\hline
\end{tabular}

$I_{k}$ denotes the $(k \times k)$ identity matrix.

\section{Data}

The estimation of the Taylor rule is done with monthly data from 1975:1 to 2007:12.

\subsection{Dependent Variable}

The choice of the monetary policy instrument entering the Taylor rule as dependent variable is not as clear-cut as in other countries. In the United States there is a wide consensus to use the federal funds rate, whereas in Switzerland the literature mentions a variety of possibilities. The SNB changed its monetary policy concept several times during the period under consideration. ${ }^{9}$ The closest analog to the federal funds rate would be the repo-overnight index of the SNB. However, this index is not available over the whole sample period and is, in contrast to the Libor, never explicitly mentioned in the monetary policy concept of the SNB. As Libor and the repo-overnight index move more or less together, I use Libor as dependent variable in my analysis. ${ }^{10}$ The Libor series is taken from Datastream.

\subsection{Explanatory Variables}

In order to estimate the proposed Taylor rule and the transition probabilities, data for the output gap, inflation, and the exchange rate gap are needed. The data are taken from Datastream. All series are seasonally adjusted and given in percent. Inflation is measured by the average change in the consumer price index over the preceding 12 months at an annual rate. The exchange rate gap is computed

9 For more information concerning the SNB's monetary policy see RICH (2003).

10 Dueker and Fischer (1995) use the growth rate of the monetary base, whereas Elkhoury (2006) takes Libor as dependent variable. CUCHE (2000) considers several variables ranging from monetary aggregates to Libor and the call rate. 
as the deviation of the logarithm of the real exchange rate from its HP trend. ${ }^{11} \mathrm{~A}$ positive exchange rate gap indicates an appreciation of the Swiss franc relative to its trend. Swiss real GDP is only available at a quarterly rate. I interpolate GDP using the approach proposed by CHow and LiN (1971). Basically, their idea is to extract a signal from monthly series related to GDP and then use this signal together with the quarterly GDP observations to construct monthly GDP figures. More information is given in the Appendix. The output gap is computed as the deviation of the logarithm of real GDP from its HP trend.

As already pointed out by FRIEDMAN (1961), the economy reacts with considerable lags to monetary policy actions. ${ }^{12}$ To allow for these dynamics, I estimate a forward-looking Taylor rule depending on expected future variables. I assume that the central bank in period $t$ knows the value of the exchange rate gap in $t$, but not the value of the output gap in $t$, due to lags in the availability of GDP figures. More specifically, the values of $k, q$, and $w$ in (7) are 0,12 , and 0 , respectively. Thus, the Taylor rule becomes

$$
i_{t}=\left(1-\rho_{S_{t}^{\rho}}\right)\left[\delta_{S_{t}}+\beta_{1 S_{t}} \tilde{y}_{t}+\beta_{2 S_{t}} E\left(\pi_{t+12}\right)+\beta_{3 S_{t}} \tilde{e}_{t}\right]+\rho_{S_{t}^{\rho}} i_{t-1}+u_{t},
$$

where $\tilde{y}_{t}=E\left(y_{t}\right)-y_{t}^{*}$ and $\tilde{e}_{t}=e_{t}-e_{t}^{*}$. Hence, the SNB is assumed to react to the expected contemporaneous output gap, to the expected one year ahead inflation rate, and to the actual contemporaneous exchange rate gap. One may wonder why I assume that the SNB reacts to the one year ahead inflation rate but to the contemporaneous exchange rate gap. The reason for this particular specification is twofold. First, the reaction of exchange rates to changes in interest rates is much faster than the reaction of inflation. Second, it is very difficult to adequately forecast future exchange rates.

Estimation of the Taylor rule given by (34) requires knowledge of the expected output gap and inflation. One way of handling expectations is to use forecasts based on VARs. ${ }^{13}$ I include the interest rate, the output gap, inflation, and the exchange rate gap as endogenous variables. In addition to the twelve lags of the endogenous variables, a constant enters as exogenous variable. One drawback of the VAR procedure is the inconsistency regarding the expectation formation for

11 The real exchange rate index for Switzerland used here is a weighted average of the real exchange rates with respect to the 24 most important trade partners. The weights are given by the export shares.

12 Bernanke and miHov (1995) provide evidence for lags in the reaction of macroeconomic variables to monetary policy using a semi-structural VAR approach.

13 Wesche (2003) pursues the same approach. 
the one year ahead inflation rate. Namely, the expected inflation rate depends on lagged interest rates, which are computed from the VAR and not from the state-dependent Taylor rule. Hence, for expectations to be rational they should be state-dependent. Consequently, the estimation of the expected variables should be done simultaneously with the estimation of the unknown parameters in the Taylor rule. This would complicate things drastically with probably minor benefits in form of more accurate results. Due to this and to the widespread use of VARs to produce forecasts of macroeconomic variables, I abstract from this problem. Furthermore, note that the resulting forecasts actually are in-sample predictions as they are based on estimated parameters using information from the whole sample.

\section{Results}

This section discusses the results. First, the estimation results for the Taylor rule specified in (7) with the variance restricted to be state-independent are presented as this model specification yields the largest value for the marginal likelihood. Second, a few results of alternative models are shown. Third, the different models are compared with help of Bayes factors. And finally, a few tests for robustness regarding the choice and timing of the data are commented on.

\subsection{Benchmark Model}

Here I estimate the Taylor rule specified in equation (7) assuming that the variance of $u_{t}$ is constant accross states, i.e. $\sigma_{s_{t}^{\sigma}}^{2}=\sigma^{2}$. The estimated parameters are reproduced in Table 2.

Except for $\delta_{1}$, the numerical standard errors and the difference between the means and medians are negligible. The estimates of $\rho$ point to a regime with a high degree of interest rate smoothing, $S_{t}^{\rho}=0$, and a more active regime with a lower value of the smoothing parameter, $S_{t}^{\rho}=1$.

The estimates for $\boldsymbol{\beta}$ reveal that in regime 1 there is only a significant reaction to inflation. Its estimate implies an increase in the interest rate of 1.3 percentage points when inflation is one percentage point above target. Regime 0 shows a bigger coefficient on inflation which also is significantly different from zero and satisfies the Taylor principle. In contrast to regime 1 , however, the reaction to the exchange rate gap is statistically significant as well. When the exchange rate is one percent above trend then the interest rate decreases by 0.88 percentage points. Interestingly, the reaction to the output gap is not significant in either 
regime. Using (6), the target for inflation is $2.0 \%$ and $4.0 \%$ in state 0 and 1 , respectively. However, the $95 \%$ highest posterior density intervals for $\delta$ are too large to make the statement that regime 1 has a statistically higher inflation target than regime 0 . Summarizing, the two regimes for $\beta$ are similar, however, regime 0 shows a significant coefficient on the exchange rate gap.

Table 2: Estimated Parameters

\begin{tabular}{|c|c|c|c|c|c|}
\hline \multirow[b]{3}{*}{$\rho_{0}$} & \multicolumn{5}{|c|}{ Posterior } \\
\hline & Mean & Median & Std. dev. & 95\%-HPDI & NSE \\
\hline & 0.967 & 0.971 & 0.021 & {$[0.927, \quad 1.000]$} & 0.0001 \\
\hline$\rho_{1}$ & 0.767 & 0.770 & 0.055 & {$[0.663,0.873]$} & 0.0003 \\
\hline$\delta_{0}$ & -0.734 & -0.704 & 0.866 & {$[-2.477, \quad 1.033]$} & 0.0041 \\
\hline$\delta_{1}$ & 0.023 & -0.087 & 1.088 & {$[-1.999, \quad 2.376]$} & 0.0051 \\
\hline$\beta_{10}$ & 1.509 & 1.501 & 1.235 & {$[-0.910, \quad 4.058]$} & 0.0058 \\
\hline$\beta_{11}$ & 0.942 & 1.072 & 1.392 & {$[-1.978, \quad 4.599]$} & 0.0066 \\
\hline$\beta_{20}$ & 2.004 & 1.947 & 0.332 & {$[1.443,2.685]$} & 0.0016 \\
\hline$\beta_{21}$ & 1.314 & 1.460 & 0.565 & {$[0.139, \quad 2.126]$} & 0.0027 \\
\hline$\beta_{30}$ & -0.883 & -0.822 & 0.388 & {$[-1.776,-0.247]$} & 0.0018 \\
\hline$\beta_{31}$ & -0.813 & -0.794 & 0.436 & {$[-1.655, \quad 0.055]$} & 0.0021 \\
\hline$\sigma$ & 0.115 & 0.115 & 0.013 & {$[0.091, \quad 0.143]$} & 0.0001 \\
\hline$p^{00}$ & 0.606 & 0.632 & 0.235 & {$[0.174, \quad 0.993]$} & 0.0011 \\
\hline$p^{11}$ & 0.547 & 0.547 & 0.217 & {$[0.158, \quad 0.981]$} & 0.0010 \\
\hline$q^{00}$ & 0.827 & 0.821 & 0.101 & {$[0.667,0.996]$} & 0.0005 \\
\hline$q^{11}$ & 0.523 & 0.468 & 0.229 & {$[0.205,0.996]$} & 0.0011 \\
\hline
\end{tabular}

95\%-HPDI gives the bounds of the 95\% highest posterior density intervals. NSE denotes numerical standard errors (see GeweKe, 1992, for details).

The transition probabilities $p^{00}$ and $p^{11}$ imply average durations of states $S_{t}=0$ and $S_{t}=1$ of 2 months each. ${ }^{14}$ The estimates for $q^{00}$ and $q^{11}$ suggest a longer duration of the regime with a high smoothing parameter (6 months) than the one with the more active reaction (2 months). The regime probabilities for $S_{t}^{\rho}$ and $S_{t}$ are shown in Figure 1. From the top graph it can be seen that the monetary policy

14 The average duration of regime $i$ can be computed as $1 /\left(1-p^{i i}\right)$. 
Figure 1. Regime Probabilities
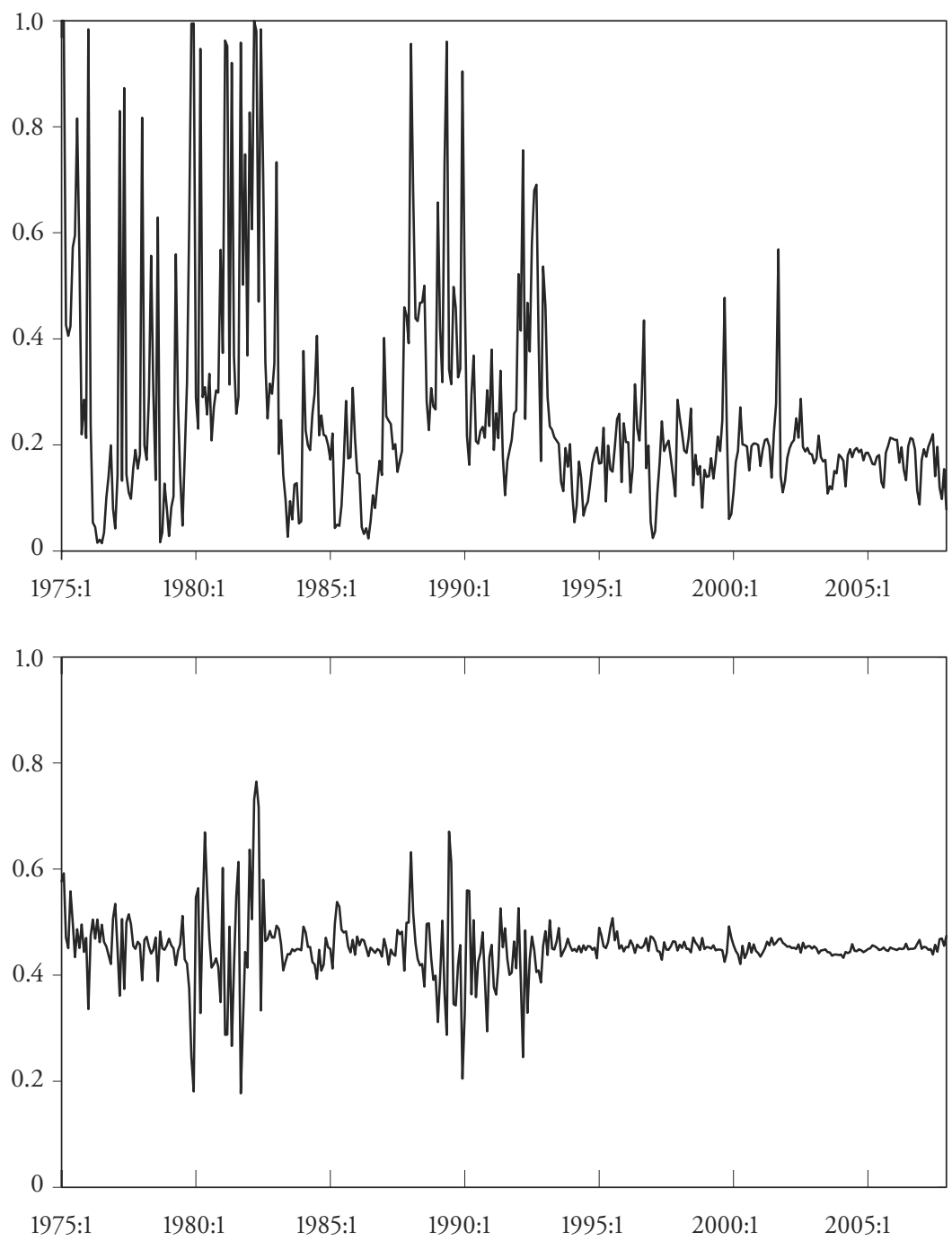

Top: Probability of regime with smaller smoothing parameter, $P\left(S_{t}^{\rho}=1 \mid Y_{T}\right)$.

Bottom: Probability of regime with smaller reaction to inflation, $P\left(S_{t}=1 \mid Y_{T}\right)$. 
regime is mostly characterized by a large degree of smoothing. There are short periods, especially in the first half of the sample, where the more active regime is in place. The graph in the bottom panel gives the regime probabilities for the $\boldsymbol{\beta}$-coefficients. There are very few periods that are attributed to regime 1, i.e. the regime with only a significant reaction to inflation. However, the regime probabilities are close to 0.5 suggesting that there is not a very clear distinction between the two regimes. Therefore, the next section presents results for the benchmark model with $\boldsymbol{\beta}$ restricted to be state-independent.

Figure 2 shows the Libor and the explanatory variables. ${ }^{15}$ The periods identified as originating from the active regime, $P\left(S_{t}^{\rho}=1 \mid Y\right)>0.5$, are shaded in gray. Broadly speaking, the active regime prevailed mainly in periods with large changes in the interest rate, relatively large changes in inflation and large and sharp deviations of the exchange rate from trend. Table 3 gives the exact dates for which $P\left(S_{t}^{\rho}=1 \mid Y\right)>0.5$ is true. Many of these dates are attributed to non-standard or active monetary policy actions. This can be seen from a few examples: ${ }^{16}$

Table 3: Dates for $S_{t}^{\rho}=1$

\begin{tabular}{lllll} 
Jan. 1975 & May 1978 & Sep. 1981 & Jan. 1983 & Jan. 1992 \\
Feb. 1975 & Nov. 1979 & Nov. 1981 & Jan. 1988 & Mar. 1992 \\
Aug. 1975 & Dec. 1979 & Jan. 1982 & Feb. 1988 & Sep. 1999 \\
\hline Jan. 1976 & Mar. 1980 & Mar. 1982 & Jan. 1989 & Sep. 2001 \\
Mar. 1977 & Feb. 1981 & Apr. 1982 & Apr. 1989 & \\
May 1977 & Mar. 1981 & Jun. 1982 & May 1989 & \\
Jan. 1978 & May 1981 & Jul. 1982 & Dec. 1989 &
\end{tabular}

- Jan./Feb. 1975: After the switch to flexible exchange rates, the Swiss franc experienced a strong real appreciation. At the beginning of 1975, the SNB tried to slow down the appreciation of the Swiss franc.

- Oct. 1978: In October 1978, the SNB temporarily adopted an exchange rate target in order to counteract the huge appreciation of the Swiss franc.

15 The figure shows the data in the way they enter the Taylor rule. That is, in period $t$ the exchange rate gap in $t$, the interest rate in $t$, expected inflation for $t+12$, and the expected output gap for $t$ are depicted.

16 See again Rich (1997) for an analysis of Swiss monetary policy. 


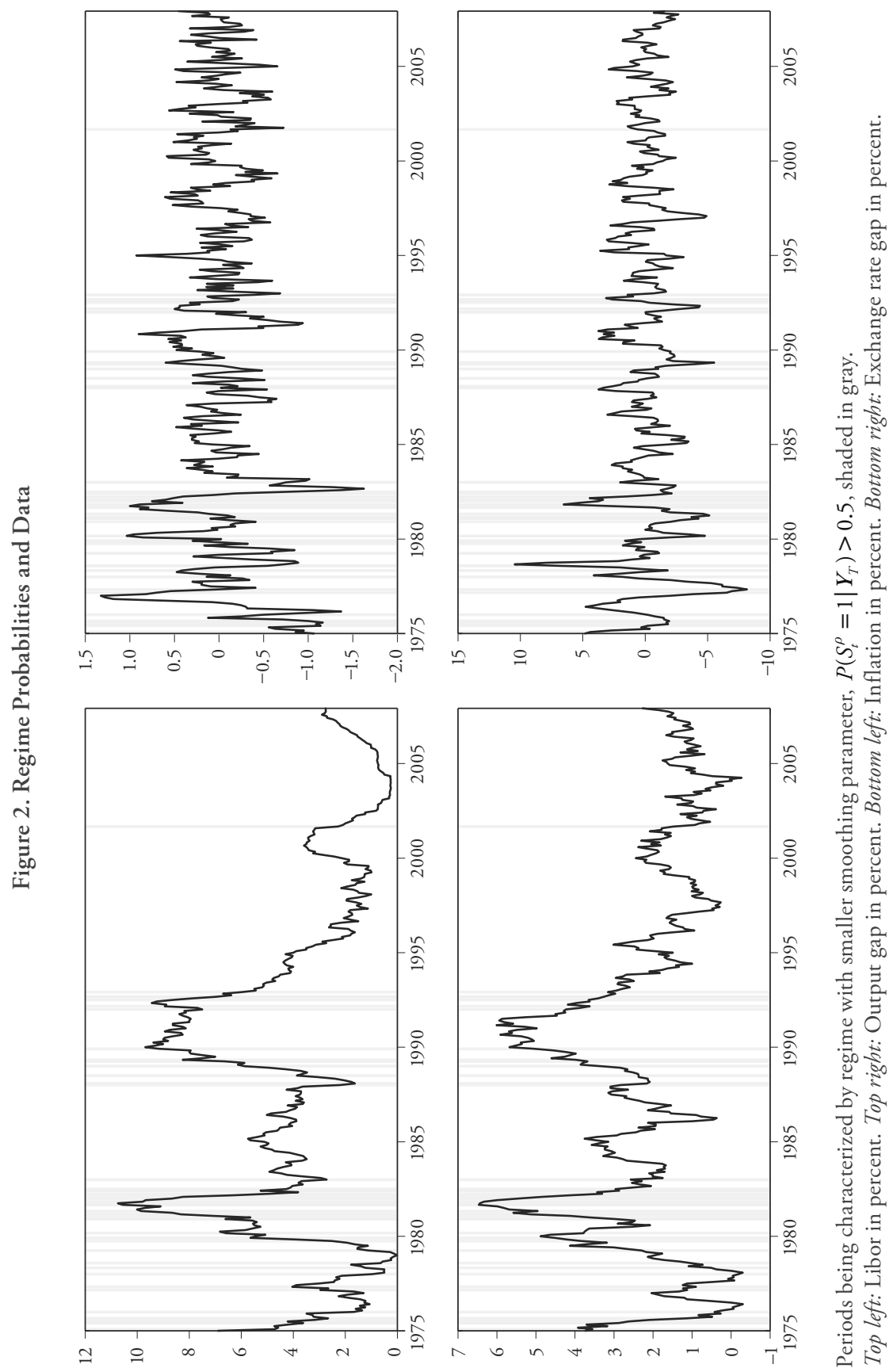


Surprisingly, however, this period is not captured as a shift in regimes. Maybe, this is due to the factthat the changes in interest rates were not as pronounced as in periods identified as regime shifts.

- Nov./Dec. 1979: At the end of 1979, inflation rose rapidly mainly due to the oil crisis in the wake of the Iranian revolution and the weakness of the Swiss franc resulting in high import prices. As a reaction the SNB increased interest rates sharply.

- Sep. 1981: In the third quarter of 1981, the Swiss economy was characterized by increasing inflation and a large depreciation of the Swiss franc. Hence, the SNB increased interest rates which successfully induced an appreciation of the exchange rate.

- Jan. 1988: In 1988 the SNB introduced the Swiss Interbank Clearing system. This electronic interbank payments system abruptly reduced the demand for base money and resulted in a sharp decline of the interest rate.

- Apr./May 1989: The SNB tightened monetary policy in order to counteract the depreciation of the Swiss franc resulting from the high interest rates set by the German Bundesbank and in order to lower inflation which was picking up due to the profound growth of the Swiss economy.

- Dec. 1989: After the oil price shock at the end of 1989, the SNB decided to follow a restrictive monetary policy in order to lower inflation.

- Mar. 1992: In March 1992, the Swiss franc depreciated sharply after the passage of the Maastricht Treaty and the resulting prospect of a new European currency. To fight this depreciation the SNB tightened monetary policy.

- Sep. 2001: The SNB lowered its target zone for the Libor by 50 basis points in September 2001 to counteract the sharp appreciation of the Swiss franc amid political and economic uncertainty originating from the terror attacks on the World Trade Center.

Generally speaking, most switches from the smooth to the active regime are due to the SNB's decision to counteract large depreciations and appreciations. As an open economy, the exchange rate plays an important role in Switzerland. In the words of Baltensperger, Hildebrand, and Jordan (2007),

The Swiss economy is regularly subjected to the negative effects of exchange rate shocks, other financial market disturbances as well as oil and energy price shocks. The ability to respond adequately to such disturbances is regarded as essential, in order to protect the economy from unwelcome cyclical fluctuations and maintain the stability of the financial system.

This suggests that the SNB exhibits a state-contingent monetary policy. Although inflation and the output gap are its primary targets, it also has to take the 
exchange rate into account when deciding on its policy. This state-contingent nature of the SNB's monetary policy is well documented in the examples mentioned above.

The actual and estimated interest rates are shown in Figure 3. The estimated target interest rate is given by (4) and calculated as the average over all Gibbs sampling iterations. The estimated target interest rate sketches the main movements of the actual interest rate. However, it is more volatile than the observed series. This feature is eliminated in the plot of the estimated nominal interest rate with interest rate smoothing. ${ }^{17}$ The actual and the implied interest rate are quite close, but now the interest rate does not reproduce each individual fluctuation resulting in a too smooth series.

\subsection{Alternative Specifications}

In this section, I present the results for two alternative specifications of (7) which yield interesting results. The first model is identical to the benchmark model presented in the previous section but the parameters in $\boldsymbol{\beta}$ are state-independent, i.e.

$$
\begin{gathered}
i_{t}=\left(1-\rho_{S_{t}^{\rho}}\right)\left[\delta+\beta_{1} \tilde{y}_{t}+\beta_{2} E\left(\pi_{t+12}\right)+\beta_{3} \tilde{e}_{t}\right]+\rho_{S_{t}^{\rho}} i_{t-1}+u_{t}, \\
u_{t} \sim N\left(0, \sigma^{2}\right) .
\end{gathered}
$$

The marginal likelihood of this model is lower than the one from the benchmark model (see the next section). But since the regime probabilities for $S_{t}$ were close to 0.5 most of the time in the benchmark model, we may gain further insights from restricting the $\boldsymbol{\beta}$ coefficients to be state-independent.

The parameter estimates are shown in Table 4. Again, an active and a smooth regime can be distinguished. Except for the constant, all parameters are statistically significant and show the expected signs. Furthermore, $\beta_{2}$ satisfies the Taylor principle. The regime probabilities for the active regime, $S_{t}^{\rho}=1$, are not reported since they are almost identical to those from the benchmark model given in Figure 1.

17 Here, the lagged interest rates entering the Taylor rule as explanatory variables are given by the interest rates implied by the model and not by the actual observations. If the actually observed interest rates were used then the difference between the two lines would hardly be visible. 
Figure 3. Interest Rates
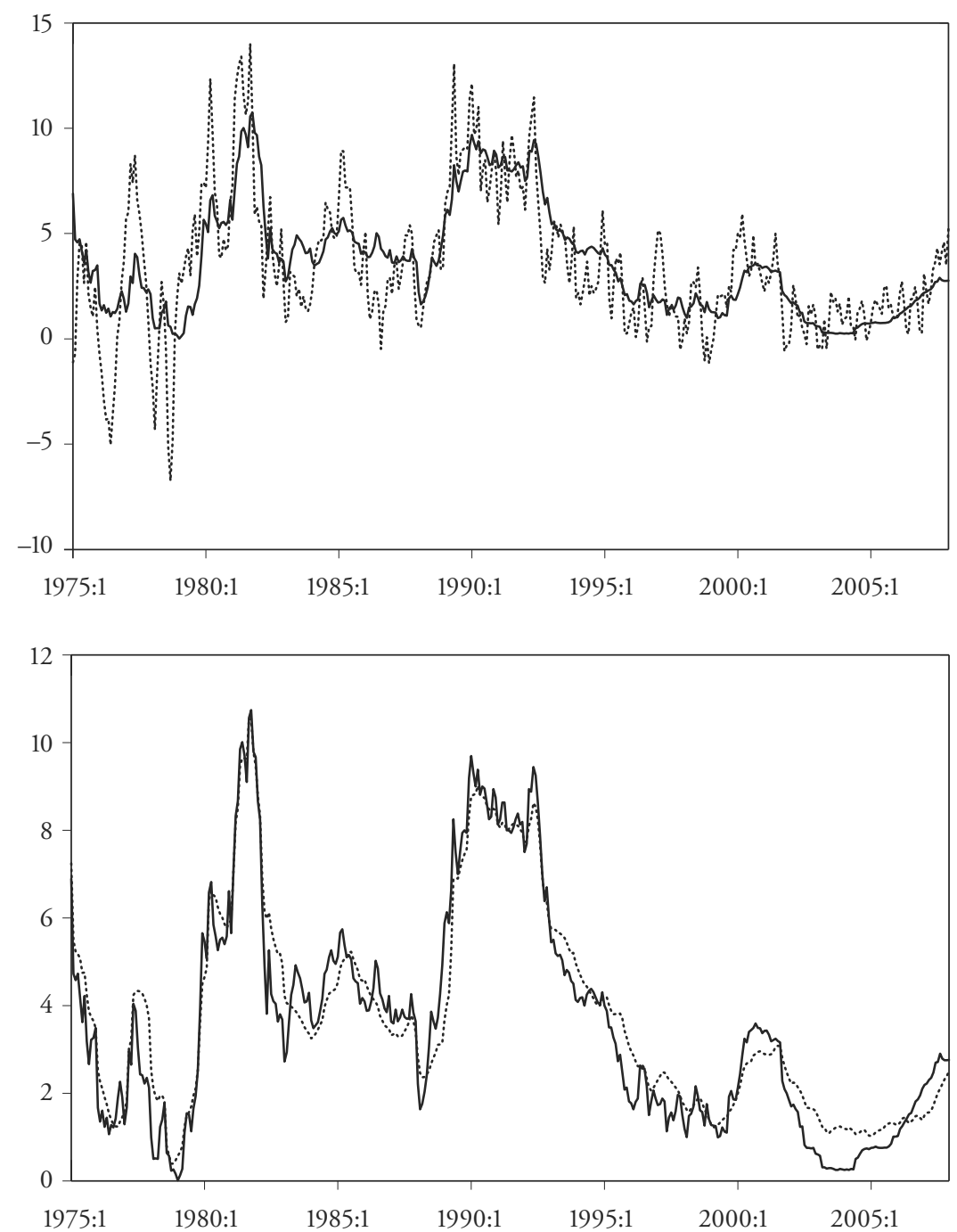

Actual nominal rate of interest (solid line) in percent.

Top: Estimated target nominal rate of interest (dashed line) in percent.

Bottom: Estimated nominal rate of interest (dashed line) in percent. 
Table 4: Estimated Parameters

\begin{tabular}{|c|c|c|c|c|c|}
\hline \multirow{3}{*}{$\rho_{0}$} & \multicolumn{5}{|c|}{ Posterior } \\
\hline & Mean & Median & Std. dev. & 95\%-HPDI & NSE \\
\hline & 0.963 & 0.963 & 0.016 & {$[0.931, \quad 0.992]$} & 0.0001 \\
\hline$\rho_{1}$ & 0.647 & 0.651 & 0.053 & {$[0.542, \quad 0.742]$} & 0.0002 \\
\hline$\delta$ & -0.679 & -0.662 & 0.367 & {$[-1.415, \quad 0.025]$} & 0.0017 \\
\hline$\beta_{1}$ & 1.140 & 1.139 & 0.429 & {$[0.298,1.998]$} & 0.0020 \\
\hline$\beta_{2}$ & 1.797 & 1.794 & 0.114 & {$[1.578, \quad 2.025]$} & 0.0005 \\
\hline$\beta_{3}$ & -0.667 & -0.659 & 0.112 & {$[-0.888,-0.455]$} & 0.0005 \\
\hline$\sigma$ & 0.113 & 0.113 & 0.010 & {$[0.095, \quad 0.133]$} & 0.0000 \\
\hline$q^{00}$ & 0.845 & 0.850 & 0.050 & {$[0.747, \quad 0.936]$} & 0.0002 \\
\hline$q^{11}$ & 0.337 & 0.333 & 0.111 & {$[0.125, \quad 0.551]$} & 0.0005 \\
\hline
\end{tabular}

95\%-HPDI gives the bounds of the $95 \%$ highest posterior density intervals. NSE denotes numerical standard errors (see GeweKe, 1992, for details).

The second model considered here assumes $\rho$ and the parameters in $\boldsymbol{\beta}$ to be stateindependent, however, the variance is allowed to switch between two states, i.e.

$$
\begin{gathered}
i_{t}=(1-\rho)\left[\delta+\beta_{1} \tilde{y}_{t}+\beta_{2} E\left(\pi_{t+12}\right)+\beta_{3} \tilde{e}_{t}\right]+\rho i_{t-1}+u_{t}, \\
u_{t} \sim N\left(0, \sigma_{S_{t}^{\sigma}}^{2}\right) .
\end{gathered}
$$

Table 5 gives the corresponding estimates. The reactions to inflation and the exchange rate gap are statistically significant but not the one to the output gap. State 0 is a regime with low variance and an average duration of 22 months, while state 1 is a high variance regime with an average duration of 16 months. The regime probabilities for the high variance state are depicted in Figure 4 and the exact dates are given in Table 6. From the top panel it is obvious that all periods captured by the active regime in the benchmark model (shaded in gray) are characterized by the high variance regime in the alternative model specification. The graph in the bottom panel draws the Libor and the periods being characterized by the high variance regime are shaded in gray. We see that the model captures periods with large and abrupt changes in the interest rate as high variance regimes. Hence, this model delivers a different interpretation to the one obtained through the benchmark model which identifies a few periods with a 


\section{Figure 4. Regime Probabilities}
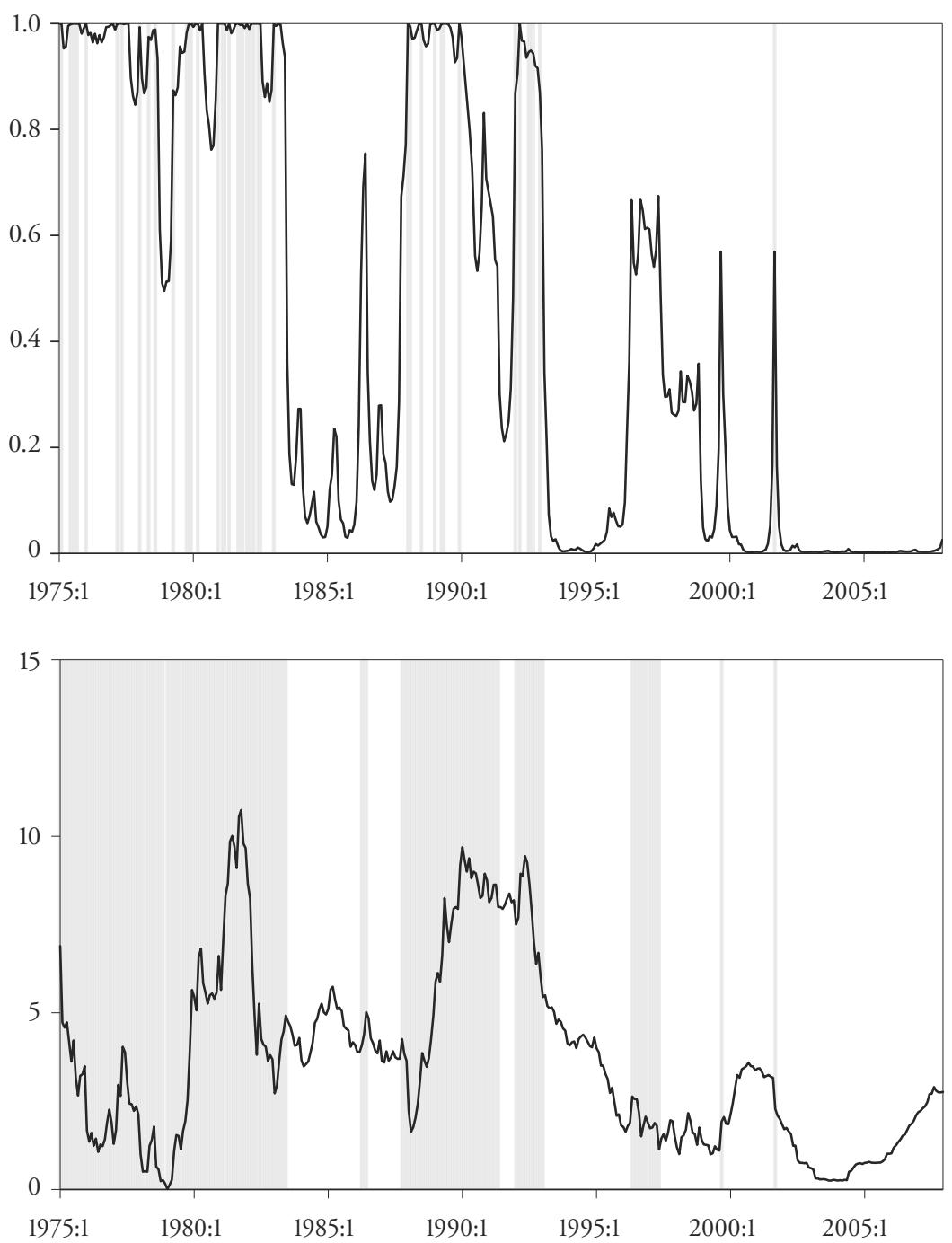

Top: Probability of regime with higher variance (solid line), $P\left(S_{t}^{\sigma}=1 \mid Y_{T}\right)$. Periods being characterized by regime with smaller smoothing parameter from benchmark model, $P\left(S_{t}^{\rho}=1 \mid Y_{T}\right)>0.5$, shaded in gray.

Bottom: Libor in percent (solid line). Periods being characterized by regime with higher variance, $P\left(S_{t}^{\sigma}=1 \mid Y_{T}\right)$, shaded in gray. 
more active reaction of the interest rate to the target interest rate. By contrast, the alternative model attributes this feature to higher variances in monetary policy shocks, i.e. the part of monetary policy left unexplained by the variables in the Taylor rule. Model comparison performed in the next section will show that the marginal likelihood of this alternative model is smaller than the one from the benchmark model.

Table 5: Estimated Parameters

\begin{tabular}{|c|c|c|c|c|c|}
\hline & \multicolumn{5}{|c|}{ Posterior } \\
\hline & Mean & Median & Std. dev. & 95\%-HPDI & NSE \\
\hline$\rho$ & 0.936 & 0.936 & 0.016 & {$[0.904, \quad 0.967]$} & 0.0001 \\
\hline$\delta$ & -0.165 & -0.159 & 0.470 & {$[-1.118, \quad 0.734]$} & 0.0022 \\
\hline$\beta_{1}$ & 0.656 & 0.661 & 0.721 & {$[-0.746,2.105]$} & 0.0034 \\
\hline$\beta_{2}$ & 1.484 & 1.492 & 0.222 & {$[1.041, \quad 1.905]$} & 0.0010 \\
\hline$\beta_{3}$ & -1.015 & -0.958 & 0.331 & {$[-1.596,-0.519]$} & 0.0016 \\
\hline$\sigma_{0}$ & 0.039 & 0.038 & 0.011 & {$[0.020, \quad 0.059]$} & 0.0001 \\
\hline$\sigma_{1}$ & 0.402 & 0.395 & 0.063 & {$[0.290, \quad 0.530]$} & 0.0003 \\
\hline$r^{00}$ & 0.954 & 0.960 & 0.030 & {$[0.898, \quad 0.998]$} & 0.0001 \\
\hline$r^{11}$ & 0.939 & 0.944 & 0.033 & {$[0.876, \quad 0.992]$} & 0.0002 \\
\hline
\end{tabular}

95\%-HPDI gives the bounds of the $95 \%$ highest posterior density intervals. NSE denotes numerical standard errors (see GeweKe, 1992, for details).

Table 6: Dates for $S_{t}^{\sigma}=1$

\begin{tabular}{ll} 
Jan. 1975 - Nov. 1978 & Jan. 1992 - Jan. 1993 \\
\hline Jan. 1979 - Jun. 1983 & May 1996 - May 1997 \\
Apr. 1986 - Jun. 1986 & Sep. 1999 \\
Oct. 1987 - May 1991 & Sep. 2001
\end{tabular}




\subsection{Model Comparison}

This section computes Bayes factors for various model specifications and compares them with the values suggested in Kass and RafterY (1995). In doing so, the marginal likelihoods of the different models have to be calculated, which is accomplished by bridge sampling. ${ }^{18}$

The results of the model comparisons are summarized in Table 7. In addition to the benchmark model $\left(\rho_{S_{t}^{\rho}}, \boldsymbol{\beta}_{S_{t}}, \sigma^{2}\right)$, the first alternative model $\left(\rho_{S_{t}^{\rho}}, \boldsymbol{\beta}, \sigma^{2}\right)$, and the second alternative model $\left(\rho, \boldsymbol{\beta}, \sigma_{s^{\sigma}}^{2}\right)$, two other models are included. ${ }^{19}$ $\left(\rho_{S^{\rho}}, \boldsymbol{\beta}_{S_{t}}, \sigma_{S_{t}^{\sigma}}^{2}\right)$ is identical to the benchmark model but also allows the variance to depend on a different state, $S_{t}^{\sigma}$. Finally, $\left(\rho, \boldsymbol{\beta}, \sigma^{2}\right)$ is a linear Taylor rule where all coefficients and the variance are state-independent.

Table 7. Model Comparison

\begin{tabular}{lccccc}
\hline & $\left(\rho_{S_{t}^{\rho}}, \beta_{S_{t}}, \sigma^{2}\right)$ & $\left(\rho_{S_{t}^{\rho}}, \beta, \sigma^{2}\right)$ & $\left(\rho, \beta, \sigma_{S_{t}^{\sigma}}^{2}\right)$ & $\left(\rho_{S_{t}^{\rho}}, \beta_{S_{t}}, \sigma_{S_{t}^{\sigma}}^{2}\right)$ & $\left(\rho, \beta, \sigma^{2}\right)$ \\
$\log (\mathrm{ML})$ & -108.49 & -148.98 & -124.03 & -131.19 & -248.88 \\
\hline $2 \log \left(\mathrm{B}_{k l}\right)$ & $\left(\rho_{S_{t}^{\rho}}, \beta_{S_{t}}, \sigma^{2}\right)$ & $\left(\rho_{S_{t}^{\rho}}, \beta, \sigma^{2}\right)$ & $\left(\rho, \beta, \sigma_{S_{t}^{\sigma}}^{2}\right)$ & $\left(\rho_{S_{t}^{\rho}}, \beta_{S_{t}}, \sigma_{S_{t}^{\sigma}}^{2}\right)$ & $\left(\rho, \beta, \sigma^{2}\right)$ \\
$\left(\rho_{S_{t}^{\rho}}, \beta_{S_{t}}, \sigma^{2}\right)$ & - & 80.99 & 31.09 & 45.41 & 280.78 \\
$\left(\rho_{S_{t}^{\rho}}, \beta, \sigma^{2}\right)$ & -80.99 & - & -49.90 & -35.58 & 199.79 \\
$\left(\rho, \beta, \sigma_{S_{t}^{\sigma}}^{2}\right)$ & -31.09 & 49.90 & - & 14.32 & 249.69 \\
$\left(\rho_{S_{t}^{\rho}}, \beta_{S_{t}}, \sigma_{S_{t}^{\sigma}}^{2}\right)$ & -45.41 & 35.58 & -14.32 & - & 235.37 \\
$\left(\rho, \beta, \sigma^{2}\right)$ & -280.78 & -199.79 & -249.69 & -235.37 & - \\
\hline
\end{tabular}

$\log (\mathrm{ML})$ denotes logarithm of Marginal Likelihood. Entries in the second part of the table give the values of $2 \log \left(\mathrm{B}_{k l}\right)$, where $B_{k l}=\mathrm{ML}_{k} / \mathrm{ML}_{l}$ is the Bayes factor comparing model $k$ (row) to model $l$ (column).

The first row in Table 7 gives the logarithm of the marginal likelihoods of the estimated models. The entries in the lower part denote two times the logarithm of the Bayes factors, where the model in the column dimension represents the

18 A nice exposition of how to compute marginal likelihoods in Markov switching models using the bridge sampling technique is delivered in FrÜHWIRTH-SCHNATTER (2004).

19 Several other model specifications were also estimated. However, none of them yielded a higher value for the marginal likelihood. 
null hypothesis and the model in the row dimension the alternative. Hence, high values indicate that the model in the row dimension is more likely than the model in the column dimension. E.g., the value in the first row and the second column (80.99) implies that the $\left(\rho_{S^{\rho}}, \boldsymbol{\beta}_{S_{t}}, \sigma^{2}\right)$-model is preferred to the $\left(\rho_{S_{t}^{\rho}}, \boldsymbol{\beta}, \sigma^{2}\right)$-model. In the language of KASS and RAFTERY (1995), values bigger than 10 indicate decisive evidence against the null hypothesis.

Table 7 yields the following ranking. The benchmark model is ranked first, the model where only the variance is allowed to be state-dependent second, the model where all coefficients and the variance are allowed to switch third, themodel where only the smoothing parameter is state-dependent forth, and the linear model is last. However, model comparison with Bayes factors can be problematic in models with different dimensionality and non-informative priors. ${ }^{20}$ Hence, the above ranking should be taken with a pinch of salt.

\subsection{Robustness}

Several tests for robustness of the benchmark model were performed. To check the sensitivity of the estimation results to the timing assumptions, I present the results from a Taylor rule where the interest rate reacts to actual, contemporaneous instead of expected future variables. In order to save space, the estimated parameters are not reproduced here. The estimates still suggest an active and a smooth regime, however, $\rho_{1}$ is closer to $\rho_{0}$ than before. For the $\boldsymbol{\beta}$-coefficients, regime 0 is still characterized by a significant reaction to inflation and the exchange rate gap. In regime 1, however, the reaction to inflation has now become insignificant; instead the reaction to the exchange rate gap now is significantly different from 0 . Furthermore, the regime probabilities in Figure 5 match those shown before closely.

In Section 4, I mentioned the caveat of using a VAR for the formation of the expected future variables that enter the Taylor rule, i.e. expectations should be state-dependent. However, as just shown, the basic insights do not change when current instead of expected future variables are used. Another sensitivity test is to form the expected future variables using forecasts from single equation autoregressive regressions. But again, the main conclusions drawn from the estimation results remain intact.

20 See Carlin and Louis (2000) and Koop (2003) for a more detailed discussion of this issue. 


\section{Figure 5. Regime Probabilities}
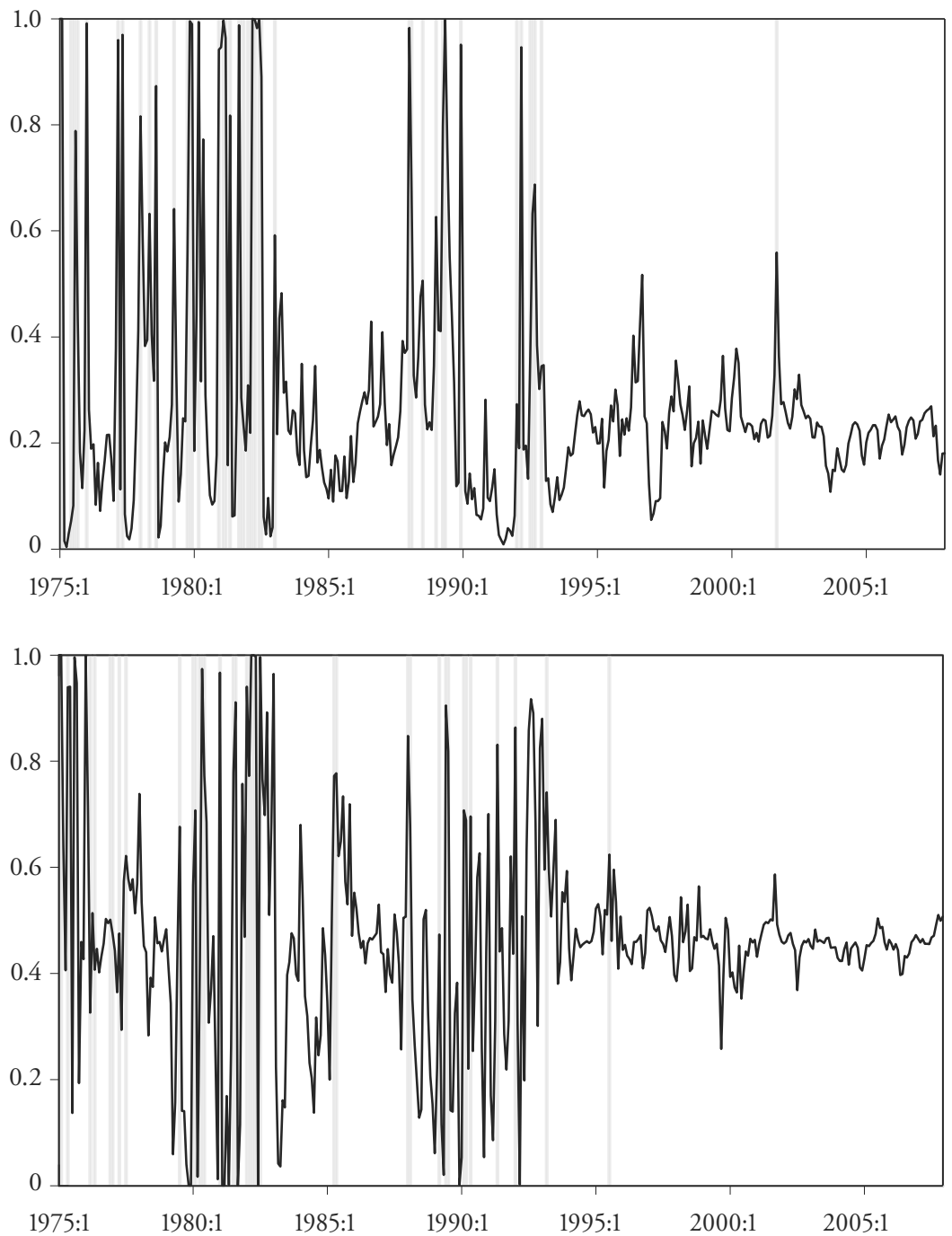

Top: Probability of regime with smaller smoothing parameter using contemporaneous data (solid line), $P\left(S_{t}^{\rho}=1 \mid Y_{T}\right)$. Periods being characterized by regime with smaller smoothing parameter using expected future data, $P\left(S_{t}^{\rho}=1 \mid Y_{T}\right)>0.5$, shaded in gray.

Bottom: Probability of regime with smaller reaction to inflation using contemporaneous data (solid line), $P\left(S_{t}=1 \mid Y_{T}\right)$. Periods being characterized by regime with smaller reaction to inflation using expected future data, $P\left(S_{t}=1 \mid Y_{T}\right)$, shaded in gray. 
Finally, the robustness of the results with respect to an alternative formation of the output and exchange rate gaps are considered. Instead of computing the trend with a Hodrick-Prescott filter, a simple linear trend was used, resulting in more persistent deviations of the variables from trend. Once more, the results give rise to the same conclusions, however, the regime probabilities for the active regime become more persistent.

\section{Conclusion}

The estimation results suggest that Swiss monetary policy is described by a smooth and an active regime. The smooth regime can be seen as the ordinary way Swiss monetary policy is conducted as it is in place $90 \%$ of times. Regime 1 shows a distinct reaction of the interest rate to specific events that interrupt the smooth regime from time to time. Many of these events induced an aggressive reaction of the Swiss National Bank to counteract immediate and large deviations of the exchange rate from its trend. More generally, this paper's analysis supports the state-contingent nature of Switzerland's monetary policy that adjusts its monetary interventions to unexpected or unusual events and puts quite some weight on keeping the Swiss franc from deviating too far from trend.

In order to account for the well known lags in monetary policy actions, I formulated a forward-looking Taylor rule. This entailed the construction of expected future variables. Furthermore, the SNB's target values have to be chosen, which is accompanied by considerable uncertainty. By using in-sample predictions from a VAR and HP trends to approximate the target values the information set is mixed up. The coefficients from the VAR and the estimation of the trends use information from the whole sample. Furthermore, I use final data and, therefore, abstract from problems like GDP data revisions and so forth. ${ }^{21}$ This implicates that the data, with which the SNB is confronted when deciding on its monetary policy actions, does not correspond to this paper's data. This could distort the estimated parameters and may conceal further insights. Hence, the estimation of a Taylor rule with real time data would be of particular interest. I leave this for future research.

21 An interesting approach is pursued by Gerlach (2007). Distinguishing between "Words" and "Deeds" of central banks, he augments the output and inflation data with central banks' assessment of these data. 


\section{Appendix}

\subsection{Gibbs Sampler}

Step 1: Draw $\rho$

(15) can be rewritten as

$$
\begin{aligned}
& \tilde{i}_{t}=\tilde{x}_{t}^{\prime} \boldsymbol{\rho}+u_{t} / \sigma_{S_{t}^{\sigma}}, \\
& \tilde{i}_{t}=\left(i_{t}-x_{t}^{\prime} \boldsymbol{\beta}\right) / \sigma_{S_{t}^{\sigma}}, \\
& \tilde{x}_{t}=\left[\left(1-S_{t}^{\rho}\right)\left(i_{t-1}-x_{t}^{\prime} \boldsymbol{\beta}\right) / \sigma_{S_{t}^{\sigma}} S_{t}^{\rho}\left(i_{t-1}-x_{t}^{\prime} \boldsymbol{\beta}\right) / \sigma_{S_{t}^{\sigma}}\right]^{\prime} .
\end{aligned}
$$

Now, $\boldsymbol{\rho}$ can be drawn from its posterior

$$
\begin{aligned}
\boldsymbol{\rho} & \sim N(\boldsymbol{u}, U) \mathrm{I}(\text { stat. }) \mathrm{I}\left(\rho_{0}>\rho_{1}\right), \\
\boldsymbol{u} & =U\left[\left(\boldsymbol{U}^{0}\right)^{-1} \boldsymbol{u}^{0}+\tilde{X}^{\prime} \tilde{\boldsymbol{I}}\right], \\
U & =\left[\left(\boldsymbol{U}^{0}\right)^{-1}+\tilde{X}^{\prime} \tilde{X}\right]^{-1}, \\
\tilde{X} & =\left[\tilde{x}_{1}, \ldots, \tilde{x}_{T}\right]^{\prime}, \\
\tilde{I} & =\left[\tilde{i}_{1}, \ldots, \tilde{i}_{T}\right]^{\prime},
\end{aligned}
$$

where rejection sampling is used to take care of $\mathrm{I}($ stat. $)$ and $\mathrm{I}\left(\rho_{0}>\rho_{1}\right)$.

Step 2: Draw $\boldsymbol{\beta}$

Alternatively, (15) can be rewritten as

$$
\begin{aligned}
& \hat{i}_{t}=\hat{x}_{t} \boldsymbol{\beta}+u_{t} / \sigma_{S_{t}^{\sigma}}, \\
& \hat{i}_{t}=\left(i_{t}-\rho_{S_{t}^{\rho}} i_{t-1}\right) / \sigma_{S_{t}^{\sigma}}, \\
& \hat{x}_{t}=\left(1-\rho_{S_{t}^{\rho}}\right) x_{t} / \sigma_{S_{t}^{\sigma}} .
\end{aligned}
$$

Now, $\boldsymbol{\beta}$ can be drawn from its posterior

$$
\begin{aligned}
& \boldsymbol{\beta} \sim N(m, M) \mathrm{I}\left(\beta_{6}>\beta_{5}\right), \\
& m=M\left[\left(M^{0}\right)^{-1} m^{0}+\hat{X}^{\prime} \hat{I}\right], \\
& M=\left[\left(M^{0}\right)^{-1}+\hat{X}^{\prime} \hat{X}\right]^{-1},
\end{aligned}
$$




$$
\begin{aligned}
\hat{X} & =\left[\hat{x}_{1}, \ldots, \hat{x}_{T}\right]^{\prime}, \\
\hat{I} & =\left[\hat{i}_{1}, \ldots, \hat{i}_{T}\right]^{\prime},
\end{aligned}
$$

where rejection sampling is used to take care of $\mathrm{I}\left(\beta_{6}>\beta_{5}\right)$

Step 3: Draw $\sigma_{0}^{2}$ and $\sigma_{1}^{2}$

The posteriors for $\sigma_{0}^{2}$ and $(1+h)$ have the following form

$$
\begin{gathered}
\sigma_{0}^{2} \sim I G\left(\left(b^{0}+T\right) / 2,\left(B^{0}+\sum_{t=1}^{T} \hat{u}_{t}^{2}\right) / 2\right), \\
\hat{u}_{t}=\left(i_{t}-\left(1-\rho_{S_{t}^{\rho}}\right) \boldsymbol{x}_{t} \boldsymbol{\beta}-\rho_{S_{t}^{\rho}} i_{t-1}\right) / \sqrt{1+h S_{t}^{\sigma}}, \\
(1+h) \sim I G\left(\left(b^{0}+F\right) / 2,\left(B^{0}+\sum_{f=1}^{F} \breve{u}_{f}^{2}\right) / 2\right), \\
\breve{u}_{f}=\left(i_{f}-\left(1-\rho_{S_{f}^{\rho}}\right) \boldsymbol{x}_{f} \boldsymbol{\beta}-\rho_{S_{f}^{\rho}} i_{f-1}\right) / \sigma_{0},
\end{gathered}
$$

where $F$ is the number of times $S_{t}^{\sigma}=1$ and the sum appearing in the equation for $(1+h)$ is taken over all values for which $S_{t}^{\sigma}=1$ is satisfied. $\sigma_{1}^{2}$ is then calculated with help of

$$
\sigma_{1}^{2}=\sigma_{0}^{2}(1+h)
$$

Step 4: Draw $\tilde{S}_{T}$

I gather the densities of $i_{t}$ conditional on the value of the state and $z_{t}$ in the vector $\boldsymbol{\kappa}_{t}$

$$
\boldsymbol{\kappa}_{t}=\left[p\left(i_{t} \mid \tilde{S}_{t}=1, \boldsymbol{z}_{t}\right), \ldots, p\left(i_{t} \mid \tilde{S}_{t}=8, \boldsymbol{z}_{t}\right)\right]^{\prime},
$$

where $p\left(i_{t} \mid \tilde{S}_{t}=i, z_{t}\right)$ is a normal density due to 3 . Define $\boldsymbol{\vartheta}_{t \mid t-1}$ as

$$
\vartheta_{t \mid t-1}=\left[p\left(\tilde{S}_{t}=1 \mid Y_{t-1}\right), \ldots, p\left(\tilde{S}_{t}=8 \mid Y_{t-1}\right)\right]^{\prime}
$$

and denote the $(8 \times 8)$ transition matrix by $\boldsymbol{P}$ 


$$
P=\left[\begin{array}{ccc}
p^{00} q^{00} r^{00} & p^{10} q^{00} r^{00} & \ldots \\
p^{01} q^{00} r^{00} & p^{11} q^{00} r^{00} & \ldots \\
\vdots & \vdots & \vdots
\end{array}\right]
$$

Let 1 and $\odot$ denote a column vector of 1 s and element by element multiplication, respectively. We can now iterate on HamiLton's (1994) filter

$$
\begin{aligned}
\boldsymbol{\theta}_{t \mid t} & =\frac{\boldsymbol{\theta}_{t \mid t-1} \odot \boldsymbol{\kappa}_{t}}{\mathbf{1}^{\prime}\left(\boldsymbol{\theta}_{t \mid t-1} \odot \boldsymbol{\kappa}_{t}\right)}, \\
\boldsymbol{\theta}_{t+1 \mid t} & =\boldsymbol{P} \boldsymbol{\theta}_{t \mid t},
\end{aligned}
$$

for $t=1, \ldots, T$. As starting values for the algorithm the unconditional probabilities $\pi^{*}$ are used

$$
\begin{gathered}
\pi^{*}=\left(W^{\prime} W\right)^{-1} W^{\prime} \boldsymbol{e}_{9}, \\
W=\left[\begin{array}{c}
I_{8}-P \\
\mathbf{1}^{\prime}
\end{array}\right],
\end{gathered}
$$

where $e_{9}$ denotes the ninth column of $I_{9}$. Given $p\left(\tilde{S}_{T}=i \mid Y_{T}\right)$, a draw for $\tilde{S}_{T}$ can be generated using a random draw from an uniform distribution over 0 to 1 . Draws for $\tilde{S}_{T}$ for $t=1, \ldots, T-1$, can be formed recursively in a straightforward way with help of the following equation

$$
p\left(\tilde{S}_{t} \mid Y_{t}, \tilde{S}_{t+1}\right)=\frac{p\left(\tilde{S}_{t+1} \mid \tilde{S}_{t}\right) p\left(\tilde{S}_{t} \mid Y_{t}\right)}{p\left(\tilde{S}_{t+1} \mid Y_{t}\right)} .
$$

Finally, $\tilde{S}_{0}$ can be drawn using the unconditional probabilities in $\pi^{*}$. Given $\tilde{S}_{t}$ the values for $S_{t}, S_{t}^{\rho}$, and $S_{t}^{\sigma}$ can be inferred.

Step 5: Draw $p^{00}$ and $p^{11}$

The posteriors for $p^{00}$ and $p^{11}$ are given by beta distributions

$$
\begin{gathered}
p^{00} \sim \operatorname{beta}\left(w^{00}+n^{00}, w^{01}+n^{01}\right), \\
p^{11} \sim \operatorname{beta}\left(w^{11}+n^{11}, w^{10}+n^{10}\right),
\end{gathered}
$$

where $n^{i j}$ is the number of times $S_{t-1}=i$ is followed by $S_{t}=j$. 
Step 6: Draw $q^{00}$ and $q^{11}$

Analogously, the posteriors for $q^{00}$ and $q^{11}$ are given by beta distributions

$$
\begin{aligned}
& q^{00} \sim \operatorname{beta}\left(w^{00}+n^{00}, w^{01}+n^{01}\right), \\
& q^{11} \sim \operatorname{beta}\left(w^{11}+n^{11}, w^{10}+n^{10}\right),
\end{aligned}
$$

where $n^{i j}$ is the number of times $S_{t-1}^{\rho}=i$ is followed by $S_{t}^{\rho}=j$.

Step 7: Draw $r^{00}$ and $r^{11}$

Analogously, the posteriors for $r^{00}$ and $r^{11}$ are given by beta distributions

$$
\begin{aligned}
& r^{00} \sim \operatorname{beta}\left(w^{00}+n^{00}, w^{01}+n^{01}\right), \\
& r^{11} \sim \operatorname{beta}\left(w^{11}+n^{11}, w^{10}+n^{10}\right),
\end{aligned}
$$

where $n^{i j}$ is the number of times $S_{t-1}^{\sigma}=i$ is followed by $S_{t}^{\sigma}=j$.

\subsection{Interpolating GDP}

I apply the methodology proposed by CHOw and Lin (1971) and (1976). Monthly GDP is assumed to be influenced by a vector of related series and, furthermore, to follow an AR(1) process. The performance of this interpolation approach for monthly GDP critically relies on the choice of the related series. Following Cuche and Hess (1999), I start from the economic identity

$$
Y=C+I+G+X-M
$$

where $Y$ is aggregate production, $C$ is private consumption, $I$ is investment, $G$ are government expenditures, $X$ are exports, and $M$ denotes imports. ${ }^{22}$ As there are no monthly series for consumption and investment, I again follow Cuche and Hess (1999) in taking retail sales as a proxy for consumption. Since in Switzerland most investment goods are imported, I approximate investment by imports of investment goods. Monthly observations of export and import volumes are

22 See Cuche and Hess (1999) for additional information concerning the choice of the related series. 
available. Government expenditures do not enter the vector of related series due to their low covariance with GDP. However, I include a constant. All related series are seasonally adjusted and taken from Datastream.

\section{References}

Albert, James H., and Siddhartha Chib (1993), "Bayes Inference via Gibbs Sampling of Autoregressive Time Series Subject to Markov Mean and Variance Shifts", Journal of Business and Economic Statistics, 11 (1), pp. 1-15.

Altavilla, Carlo, and Luigi Landolfo (2005), "Do Central Banks Act Asymmetrically? Empirical Evidence from the ECB and the Bank of England", Applied Economics, 37, pp. 507-519.

Amano, Robert, Don Coletti, and Tiff Macklem (1999), "Monetary Rules When Economic Behaviour Changes", Working Paper 81, Center for Research on Economic Fluctuations and Employment (CREFE).

Assenmacher-Wesche, Katrin (2006), "Estimating Central Banks' Preferences from a Time-Varying Empirical Reaction Function", European Economic Review, 50, pp. 1951-1974.

Baltensperger, Ernst, Philipp M. Hildebrand, and Thomas J. Jordan (2007), “The Swiss National Bank's Monetary Policy Concept - an Example of a 'Principles-Based' Policy Framework”, Economic Studies 3, Swiss National Bank.

Barro, Robert J., and David B. Gordon (1983), "A Positive Theory of Monetary Policy in a Natural Rate Model", Journal of Political Economy, 91, pp. 589-610.

Bernanke, Ben S., and Ilian Mihov (1995), "Measuring Monetary Policy", Working Paper No. 5145, NBER.

Carlin, Bradley P., and Thomas A. Louis (2000), Bayes and Empirical Bayes Methods for Data Analysis. Texts in Statistical Science Series, Boca Raton, Chapman and Hall CRC Press.

Chow, Gregory C., and AN-Loh Lin (1971), "Best Linear Unbiased Interpolation, Distribution, and Extrapolation of Time Series by Related Series", Review of Economics and Statistics, 53 (4), pp. 372-375.

Chow, Gregory C., and AN-LOH Lin (1976), "Best Linear Unbiased Estimation of Missing Observations in an Economic Time Series", Journal of the American Statistical Association, 71 (335), pp. 719-721.

Cuche, Nicolas A. (2000), "Monetary Policy with Forward-Looking Rules: The Swiss Case”, Working Papers No. 0010, Study Center Gerzensee. 
Cuche, Nicolas A., and Martin K. Hess (1999), "Estimating Monthly GDP in a General Kalman Filter Framework: Evidence from Switzerland", Working Papers No. 9902, Study Center Gerzensee.

Cunierman, Alex (1999), “The Inflation Bias Result Revisited”, Tel-Aviv University Working Paper No. 99-38.

Dueker, Michael, and Andreas M. Fischer (1995), "Inflation Targeting in a Small Open Economy: Empirical Results for Switzerland”, Working Papers No. 1995-014A, Federal Reserve Bank of St. Louis.

Elkhoury, Marwan (2006), "A Time-Varying Parameter Model of A Monetary Policy Rule for Switzerland. The Case of the Lucas and Friedman Hypothesis", Working Papers No. 01-2006, HEI.

Friedman, Milton (1961), "The Lag in Effect of Monetary Policy", Journal of Political Economy, 69, pp. 447-466.

FrüH wirth-Schnatter, Sylvia (2004), "Estimating Marginal Likelihoods for Mixture and Markov Switching Models Using the Bridge Sampling Techniques", Econometrics Journal, 7, pp. 143-167.

Gerlach-Kristen, Petra (2003), "Interest Rate Reaction Functions and the Taylor Rule in the Euro Area”, Working Paper No. 258, ECB.

Gerlach, Stefan (2003), "Recession Aversion, Output and the Kydland-Prescott Barro-Gordon Model”, Economics Letters, 81, pp. 389-394.

Gerlach, Stefan (2007), "Interest Rate Setting by the ECB, 1999-2006: Words and Deeds", International Journal of Central Banking, 3 (3), pp. 1-45.

Geweke, John (1992), "Evaluating the Accuracy of Sampling-Based Approaches to the Calculation of Posterior Moments", in: J. O. Berger, J. M. Bernardo, A. P. Dawid and A. F. M. Smith (eds), Bayesian Statistics 4, Oxford University Press, pp. 164-193.

Hamilton, James D. (1989), "A New Approach to the Economic Analysis of Nonstationary Time Series and the Business Cycle”, Econometrica, 57 (2), pp. 357-384.

Hamilton, James D. (1994), Time Series Analysis, Princeton Universtiy Press.

Kass, Robert E., and Adrian E. Raftery (1995), "Bayes Factors", Journal of the American Statistical Association, 90 (430), pp.773-795.

Kim, Chang-Jin, and Charles R. Nelson (1999), State-Space Models with Regime Switching, Cambridge, MIT Press.

Koop, Gary (2003), Bayesian Econometrics, Chichester, John Wiley.

Kuzin, Vladimir (2006), "The Inflation Aversion of the Bundesbank: A State-Space Approach", Journal of Economic Dynamics and Control, 30, pp. 1671-1686. 
Kydland, Finn E., and Edward C. Prescott (1977), "Rules Rather Than Discretion: The Inconsistency of Optimal Plans", Journal of Political Economy, 85, pp. 473-491.

Lucas, Robert E. Jr. (1976), "Econometric Policy Evalutaion: A Critique", Carnegie Rochester Conference Series on Public Policy, 1, pp. 19-46.

McNees, Stephen K. (1986), "Modeling the Fed: A Forward-Looking Monetary Policy Reaction Function”, New England Economic Review, Nov./Dec., pp. 3-8.

Owyang, Michael T., and Garey Ramey (2004), "Regime Switching and Monetary Policy Measurement", Journal of Monetary Economics, 51, pp. 1577-1597.

Persson, Torsten, and Guido Tabellini (1999), "Political Economics and Macroeconomic Policy”, in: J.B. Taylor and M. Woodford (ed.), Handbook of Macroeconomics, 1C, Amsterdam, Elsevier North-Holland, pp. 1397-1482.

Rabanal, Pau (2004), "Monetary Policy Rules and the U.S. Business Cycle: Evidence and Implications", Working Paper No. 164, IMF.

Rich, GeORg (1997), "Monetary Targets as a Policy Rule: Lessons from the Swiss Experience", Journal of Monetary Economics, 39, pp. 113-141.

Rich, Georg (2003), "Swiss Monetary Targeting 1974-1996: The Role of Internal Policy Analysis”, Working Paper No. 236, ECB.

Rudebusch, Glenn D. (2001), "Is the Fed Too Timid? Monetary Policy in an Uncertain World", Review of Economics and Statistics, 83 (2), pp. 203-217.

Ruge-Murcia, Francisco J. (2001), "The Inflation Bias when the Central Bank Targets the Natural Rate of Unemployment”, Cahiers de recherche 2001-22, Université de Montréal, Département de sciences économiques.

Sims, Christopher A., and Tao Zha (2006), "Were There Regime Switches in U.S. Monetary Policy?”, American Economic Review, 96 (1), pp. 54-81.

Smets, Frank (1998), "Output Gap Uncertainty: Does it matter for the Taylor Rule?”, Working Paper No. 60, BIS.

Svensson, Lars E.O. (1999), "Inflation Targeting: Some Extensions", Scandinavian Journal of Economics, 101 (3), pp. 337-361.

Taylor, John B. (1993), "Discretion versus Policy Rules in Practice", CarnegieRochester Conference Series on Public Policy, 39, pp. 195-214.

Wesche, Katrin (2003), "Monetary Policy in Europe: Evidence from TimeVarying Taylor Rules”, Econ Discussion Papers No. 21/2003, Bonn.

Woodford, Michael (1999), "Optimal Monetary Policy Inertia”, Working Paper No. 7261, NBER. 


\section{SUMMARY}

In this paper a Taylor rule including the exchange rate gap is estimated for Switzerland under the assumption that the parameters depend on two states governed by a Markov switching process. The estimates from a Gibbs sampler suggest the presence of a smooth and an active regime. The former is characterized by a high degree of interest rate smoothing. By contrast, the aggressive regime shows much less smoothing. The regime probabilities indicate that Swiss monetary policy is well characterized by the smooth regime with short interruptions by the active regime. Many of these few active periods can be associated with specific and unusual events. Furthermore, the analysis makes clear that often the active regime prevailed in periods where the Swiss National Bank decided to counteract sharp appreciations or depreciations of the Swiss franc. 